\title{
Patterns of recurrence of gastric cancer following curative gastrectomy depends on adjuvant chemotherapy
}

\section{ORIGINAL ARTICLE Annals of Cancer Research and Therapy}

\author{
Sumitaka Arima*1), Hiroshi Yamamoto - Takeharu Hisatsugu*2), Ryusuke Ohkuma*3), \\ Keiichi Ohsato*4), Ryuji Abe ${ }^{* 5)}$, Norio Fukuyama*6) \\ from The North Kyushu Co-operative Study Group for Cancer Chemotherapy
}

\begin{abstract}
Objective : To compare the pattern of recurrence and the survival rate after two regimens of adjuvant chemotherapy following curative resection of gastric cancer.

Design : Prospective multicentre trial.

Setting : Twenty-one departments of surgery.

Subjects : A total of 163 patients who had undergone histological curative resection.

Interventions : All patients received an intravenous bolus of mitomycin $C(20 \mathrm{mg})$ on the day of operation, and a dose of $10 \mathrm{mg}$ of the first postoperative day. They were then randomized to receive either oral tegafur $(600 \mathrm{mg} /$ day) or tegafur-uracil $(600 \mathrm{mg} /$ day) for 2 years from 2 weeks after the operation.

Main outcome measures : The pattern of recurrence and the survival rate were assessed.

Results : Tegafur-uracil reduced peritoneal recurrence when compared with tegafur. About $70 \%$ of all patients had recurrece within two years. The tegafur-uracil group had a significantly higher 7 -year survival rate than the tegafur group $(P=0.04)$.

Conclusion: The overall recurrence rate was generally lower in the tegafur-uracil group, although there was no statistical difference. Most of patients had recurrence occurred within 2 years after surgery. This finding indicates that postoperative maintenance therapy for 2 years is necessary to suppress recurrence.
\end{abstract}

Ann Cancer Res Ther 4 (2) 103 107, 1995/Received 13 Nov 1995, Accepted 22 Dec 1995

Key words : gastric cancer, adjuvant chemotherapy, pattern of recurrence

Gastric cancer shows a higher sensitivity to anticancer agents than most other types of solid cancer. Because of the possibility of recurrence after curative resection of gastric cancer, the killing of residual cancer cells by adjuvant chemotherapy is important to improve the postoperative results ${ }^{1)}$.

Oral administration of tegafur, a prodrug of 5-FU, to patients with gastric cancer has achieved fairly good results as outpatient adjuvant chemotherapy ${ }^{2-8}$.

UFT is a combination of tegafur and uracil at a molar ratio of $1: 4$, and was developed as an antitumor drug by Fujii et al. ${ }^{9}$. Both animal studies and clinical trials have revealed higher levels of 5-fluorouracil (5-FU) in the blood and tumor tissue after UFT administration compared tegafur or 5-FU ${ }^{7,10)}$. In 1994, we published the results of a 5-year follow-up of 243 gastric cancer patients included in a randomized trial of

\footnotetext{
"1) Department of Surgery, Chikushi Hospital, Fukuoka University School of Medicine

${ }^{2}$ Department of Surgery, Saga Medical School

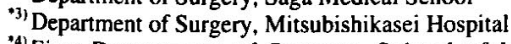

${ }^{4}$ First Department of Surgery, School of Medicine, University of Occupational and Environmental Health

-5) Department of Surgery, Kitakyushu City Medical Center Hospital

${ }^{6)}$ Department of Surgery, Memorial Kokura Hospital

Correspondence to : Sumitaka Arima, Department of Surgery, Chikushi Hospital, Fukuoka University, 377-1 Zokumyoin, Chikushino-shi, Fukuoka 818, Japan

TEL 092-921-1011, FAX 092-928-0856
}

tegafur versus $\mathrm{UFT}^{3)}$. All patients received an intravenous bolus of mitomycin $\mathrm{C}$ on the day of operation and on the first postoperative day. The two regimens had only slight toxicity (nausea, leucopenia, and hepatic impairment) and no adverse effects were observed on the central nervous system. The incidence of toxicity was low, with no significant differences between the groups. In addition, there was no significant difference in the 5-year survival rate (although the patients receiving tegafur-uracil lived longer), except for patients with histological curative resection $(\mathrm{P}=0.04)^{3)}$. The aim of the present retrospective study was to evaluate differences in the pattern of recurrence between both groups.

\section{Patients and methods}

All patients included in this prospective randomized controlled trial had undergone gastric resection during the 27-month period from October 1983 to December 1985 at 21 hospitals in the northern region of Kyushu, Japan. All patients received an intravenous bolus injection of mitomycin $\mathrm{C}$ (20 $\mathrm{mg}$ ) on the day of operation and another $10 \mathrm{mg}$ on the first postoperative day. They were then randomly assigned to one of two groups by the envelope method and received either oral tegafur (600 mg/day) or tegafur-uracil $(600 \mathrm{mg} /$ day $)$ for two years from 2 weeks postoperatively for 2 years. 
Table 1 Patients studied

\begin{tabular}{lrr}
\hline & \multicolumn{2}{c}{ Curative operation } \\
\cline { 2 - 4 } & Tegafur & \multicolumn{2}{c}{ Tagafur-uracil } \\
\hline No. who entered the trial & 81 & 82 \\
No. withdrawn & 6 & 5 \\
No. excluded & 4 & 10 \\
No. studied & 71 & 67 \\
\hline
\end{tabular}

The criteria for patient selection were as follows : macroscopic stage II, III, or IV disease ; age less than 76 years ; no evidence of synchronous or metachronous tumors ; and adequate organ function (white cell count $\geqq 4 \times 10^{9} / \mathrm{L}$, platelet count $\geqq 750,000 / \mathrm{L}$, total protein concentration $\geqq 60$ $\mathrm{g} / \mathrm{L}$ with an albumin : globulin ratio of 1.0 , serum glutamic oxaloacetic transaminase (GOT) and serum glutamic pyruvic transaminase (GPT) $\leqq 100 \mathrm{U} / \mathrm{L}$, and no protein urine. Informed consent was obtrained from all patients before enrollment.

The total number of subjects at the end of the study was 243,124 in the tegafur group and 119 in the tegafur-uracil group. Thirteen subjects were excluded because they did not have cancer $(n=2)$, they were above the age limit $(n=9)$, they had multiple carcinoma $(n=1)$, or because resection was impossible $(n=1)$. Since the 78 patients in the non-curative resection group showed the same 5-year survival rate ${ }^{23}$, they were not included in the analysis of results. Therefore, we evaluated 138 patients who had undergone curative resection before adjuvant chemotherapy, excluding 14 patients who did not take the prescribed drug or did not take it as directed (Table 1). It was previously shown that there were no significant differences between the patients with curative resection given tegafur or given tegafur-uracil (Table 2) ${ }^{3}$.

Recurrence in patients who had undergone curative resection 7 years earlier was classified into the following four patterns based on the results of laboratory tests, laparotomy, and autopsy : localized recurrence, hematogenous recurrence, peritoneal recurrence, and distant lymph node recurrence.

The staging of each patient was performed according to the Japanese guidelines for gastric cancer study ${ }^{14)}$. The significance of differences between groups was assessed by the chi-square test, the Mann-Whitney U test, and Student's $t$-test. Survival curves were constructed using the KaplanMeier method and the significance of differences was assessed by the log- rank test. A P value of less than 0.05 was considered to be significant. Recurrence hazard rates were calculated by Gehan's method ${ }^{12}$.
Table 2 Comparability of the groups

\begin{tabular}{|c|c|c|}
\hline & \multicolumn{2}{|c|}{ Curative operation } \\
\hline & $\begin{array}{l}\text { Tegafur } \\
(\mathrm{n}=71)\end{array}$ & $\begin{array}{c}\text { Tegafur-uracil } \\
(n=67)\end{array}$ \\
\hline \multicolumn{3}{|l|}{ Sex : } \\
\hline Male & $39(55)$ & $37(55)$ \\
\hline Female & $32(45)$ & $30(45)$ \\
\hline \multicolumn{3}{|l|}{ Age at operation : } \\
\hline$>35$ & $3(4)$ & $1(2)$ \\
\hline $36-55$ & $25(33)$ & $22(33)$ \\
\hline $56-75$ & $43(61)$ & $44(65)$ \\
\hline \multicolumn{3}{|l|}{ Location of tumor: } \\
\hline Upper & $11(15)$ & $17(25)$ \\
\hline Middle & $29(41)$ & $20(30)$ \\
\hline Lower & $31(44)$ & $30(45)$ \\
\hline \multicolumn{3}{|l|}{ Bormann type : } \\
\hline 0 & $9(13)$ & $7(11)$ \\
\hline 1 & $2(3)$ & $2(3)$ \\
\hline 2 & $21(30)$ & $27(40)$ \\
\hline 3 & $27(38)$ & $23(34)$ \\
\hline 4 & $6(8)$ & $7(10)$ \\
\hline 5 & $5(7)$ & $1(2)$ \\
\hline Unknown & $1(1)$ & $0(0)$ \\
\hline \multicolumn{3}{|l|}{ Size of tumour $(\mathrm{cm})$ : } \\
\hline$>5$ & $33(46)$ & $24(36)$ \\
\hline $5-10$ & $29(41)$ & $32(48)$ \\
\hline $10<$ & $9(13)$ & $11(16)$ \\
\hline \multicolumn{3}{|c|}{ Histological signs of serosal invasion : } \\
\hline Absent & $42(59)$ & $40(60)$ \\
\hline Present & $29(41)$ & $27(40)$ \\
\hline \multicolumn{3}{|c|}{ Histological signs of lymph node metastasis : } \\
\hline No & $25(35)$ & $22(33)$ \\
\hline N1 & $25(35)$ & $27(40)$ \\
\hline N2 & $18(26)$ & $18(27)$ \\
\hline N3 & $3(4)$ & $0(0)$ \\
\hline \multicolumn{3}{|c|}{ Macroscopic signs of lymph node metastasis } \\
\hline No & $5(7)$ & $6(9)$ \\
\hline N1 & $39(55)$ & $32(48)$ \\
\hline $\mathbf{N} 2$ & $20(28)$ & $28(41)$ \\
\hline N3 & $6(9)$ & $1(2)$ \\
\hline N4 & 1(1) & $0(0)$ \\
\hline \multicolumn{3}{|l|}{ Histology } \\
\hline Differentiated & $33(47)$ & $36(53)$ \\
\hline Undifferentiated & $35(49)$ & $31(47)$ \\
\hline Unknown & 3(4) & $0(0)$ \\
\hline \multicolumn{3}{|c|}{$\begin{array}{l}\text { Histological signs of infiltration } \\
\text { at the resection margins : }\end{array}$} \\
\hline Absent & $70(99)$ & $67(100)$ \\
\hline Present & $0(0)$ & $0(0)$ \\
\hline Unknown & $1(1)$ & $0(0)$ \\
\hline \multicolumn{3}{|l|}{ Histological stage : } \\
\hline $\mathrm{I}$ & $12(17)$ & $10(15)$ \\
\hline П & $19(27)$ & $21(31)$ \\
\hline III & $36(51)$ & $34(51)$ \\
\hline IV & $4(5)$ & $2(3)$ \\
\hline \multicolumn{3}{|l|}{ Operation } \\
\hline Total & $23(32)$ & $24(36)$ \\
\hline Distal partial & $46(65)$ & $39(58)$ \\
\hline Proximal partial & $2(3)$ & $3(5)$ \\
\hline Unknown & $0(0)$ & 1(1) \\
\hline \multicolumn{3}{|c|}{ Lymph node dissection } \\
\hline Ro & $0(0)$ & $0(0)$ \\
\hline RI & $1(1)$ & $4(6)$ \\
\hline R2 & $59(84)$ & $52(78)$ \\
\hline $\mathrm{R} 3$ & $11(15)$ & $11(16)$ \\
\hline
\end{tabular}

Figures are number $(\%)$ of patients 
Table 3 Recurrence patterns and times

\begin{tabular}{|c|c|c|c|c|c|c|c|}
\hline \multirow{2}{*}{$\begin{array}{c}\begin{array}{c}\text { Recurrence } \\
\text { pattern }\end{array} \\
\text { Tegafur group }\end{array}$} & \multirow[t]{2}{*}{$\begin{array}{l}\text { Recurrence } \\
\text { rate }\end{array}$} & \multicolumn{6}{|c|}{$\begin{array}{l}\text { Recurrence time (year) } \\
\sim 1 \sim 2 \sim 3 \sim 4-5 \quad 5-\end{array}$} \\
\hline & & & & & & & \\
\hline $\begin{array}{l}\text { Localized } \\
\text { recurence }\end{array}$ & $\begin{array}{r}8.5 \% \\
(6 / 71)\end{array}$ & 2 & 3 & & & 1 & 1 \\
\hline $\begin{array}{l}\text { Hematogenous } \\
\text { recurrence } \\
\text { Liver } \\
\text { Others } \\
\text { (lung, bones, etc.) }\end{array}$ & $\begin{array}{c}21.1 \% \\
(15 / 71)\end{array}$ & $\begin{array}{l}5 \\
4\end{array}$ & $\begin{array}{l}4 \\
4\end{array}$ & 1 & 2 & & \\
\hline $\begin{array}{l}\text { Peritoneal } \\
\text { recurence }\end{array}$ & $\begin{array}{l}22.5 \% * \\
(16 / 71)\end{array}$ & 8 & 4 & 2 & 2 & 1 & 1 \\
\hline $\begin{array}{l}\text { Distal lymph } \\
\text { node recurrence }\end{array}$ & $\begin{array}{r}1.4 \% \\
(1 / 71)\end{array}$ & 1 & & & & & \\
\hline \multicolumn{8}{|l|}{ Tegafur-uracil group } \\
\hline $\begin{array}{l}\text { Localized } \\
\text { recurrence }\end{array}$ & $\begin{array}{r}7.5 \% \\
(5 / 67)\end{array}$ & 2 & 3 & & & 1 & \\
\hline $\begin{array}{l}\text { Hematogenous } \\
\text { recurrence } \\
\text { Liver } \\
\text { Others } \\
\text { (lung, bones, etc.) }\end{array}$ & $\begin{array}{l}13.4 \% \\
(9 / 67)\end{array}$ & 1 & $\frac{2}{2}$ & 2 & 1 & & \\
\hline $\begin{array}{l}\text { Peritoneal } \\
\text { recurrence }\end{array}$ & $\begin{array}{l}10.4 \% * \\
(7 / 67)\end{array}$ & 3 & 2 & 1 & & & 1 \\
\hline $\begin{array}{l}\text { Distal lymph } \\
\text { node recurrence }\end{array}$ & $\begin{array}{l}1.5 \% \\
(1 / 67)\end{array}$ & & & 1 & & & \\
\hline
\end{tabular}

\section{Results}

Survival of patients with histological curative resection

The 7-year survival rate for 71 patients in the tegafur group and 67 in the tegafur-uracil group was $45 \%$ and $65 \%$, respectively. The tegafur-uracil group showed a significantly better survival rate than the tegafur group $(P=0.04)$ (Fig. 1).

\section{Timing and pattem of recurrence (Table 3)}

According to the 7-year follow-up results, recurrence occurred in 28 out of 71 patients (39\%) in the tegafur group and in 16 out of 67 patients (24\%) in the tegafur-uracil group, so the recurrence rate was lower in the latter group $(\mathrm{P}=0.07)$. Recurrence affected multiple organs in $29 \%(8 / 28)$ of the tegafur group and $31 \%(5 / 16)$ of the tegafur-uracil group. The pattern was localized recurrence in $9 \%$, hematogenous recurrence in $21 \%$, peritoneal recurrence in $23 \%$, and distant lymph node recurrence in $1 \%$ of the tegafur group. In the tegafur-uracil group, the mode of recurrence was localized in $8 \%$, hematogenous in $13 \%$, peritoneal in $10 \%$, and lymph node in $2 \%$. Excluding lymph node recurrence, the rates for the other types of recurrences tended to be lower in the tegafur-uracil group, especially in the case of peritoneal recurrence $(P=0.09)$. Recurrence generally occurred within 2 years $(71 \%$ of recurrences in the tegafur group) and $69 \%$ of recurrences in the tegafur-uracil group). However, peritoneal recurrence tended to be delayed. One localized recurrence and two peritoneal recurrences occurred after 5 years.

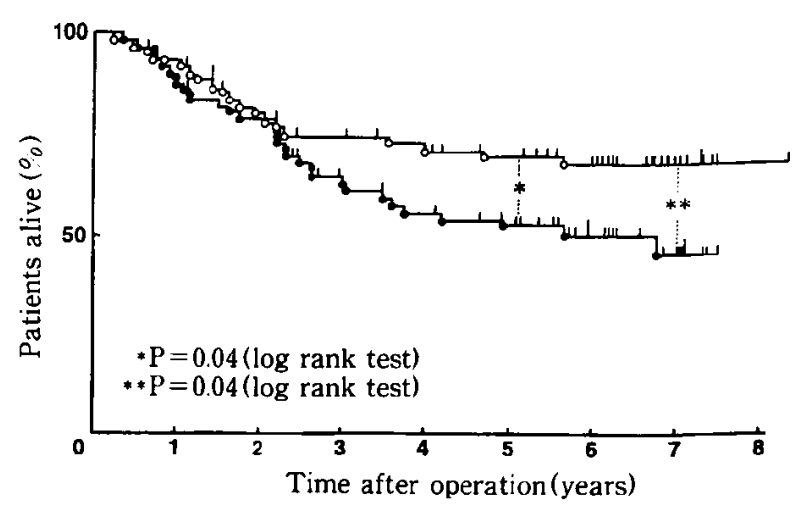

Fig. 1

Survival curves of 138 patients who underwent histological curative operations, 71 of whom received tegafur (closed circles) and 67 of whom received tegafur-uracil (open circle). Vertical marks indicate censored deaths.

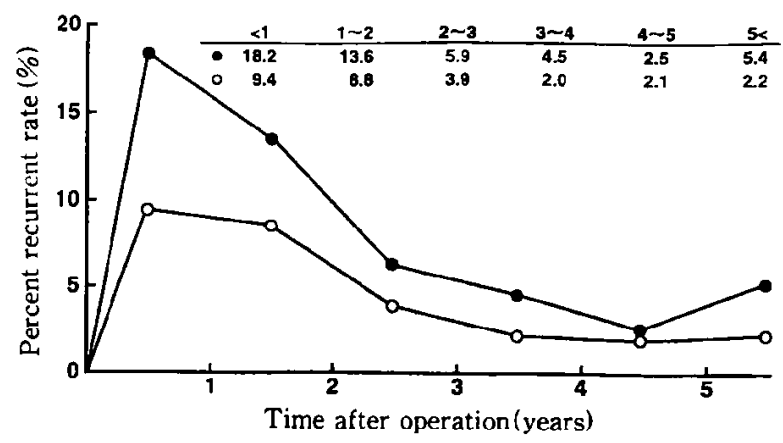

Fig. 2 Recurrence hazard rate of all cases The closed circles indicate patients who underwent curative operation and received tegafur. The open circles indicate patients who underwent curative operation and received tegafur-uracil.

\section{Pattern of recurrence and the recurrence hazard rate}

When the hazard rate of recurrence was assessed, peaks were seen in the 1 st year $(18 \%, 9 \%)$ and the 2 nd $(14 \%, 9 \%)$ years, follwed by a gradual decrease in both the tegafur and tegafur-uracil groups. The hazard rate was generally lower in the tegafur-uracil group (Fig. 2).

The recurrence hazard rates for peritoneal metastasis reached a peak (11\%) within 1 year in the tegafur group, while the rate after 1 year was lower but an increased risk was persistent. In the tegafur-uracil group, the recurrence hazard rate $(5 \%)$ was generally lower than in the tegafur group (Fig. 3). The hematogenous recurrence hazard rate was $(8 \%, 2 \%)$ in the 1 st year and $(7 \%, 4 \%)$ in the 2 nd year, followed by a gradual decrease in both groups (Fig. 4). 


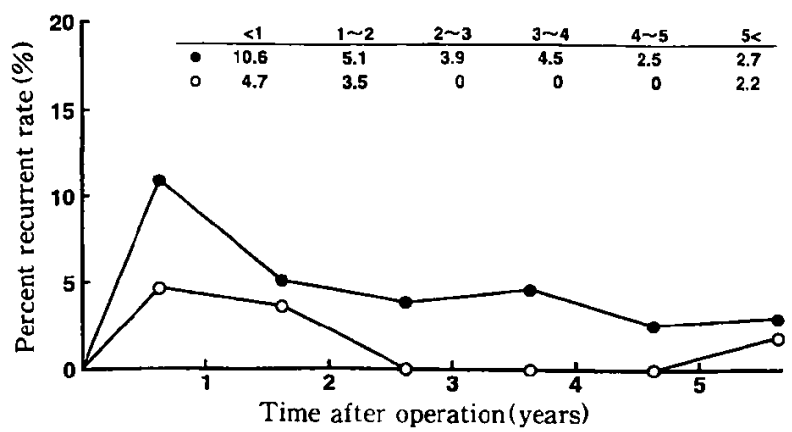

Fig. 3 Peritoneal recurrence hazard rate The closed circles indicate patients who underwent curative operation and received tegafur. The open circles indicate patients who underwent curative operation and received tegafur-uracil.

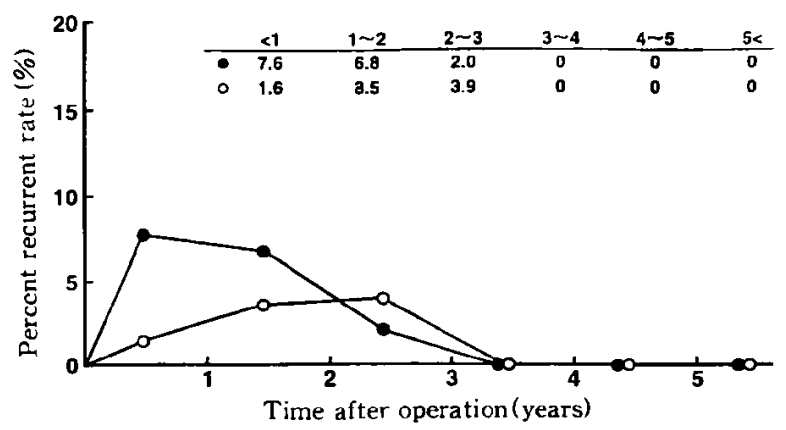

Fig. 4 Recurrence hazard rate (hematogenous relapses) The closed circles indicate patients who underwent curative operation and received tegafur. The open circles indicate patients who underwent curative operation and received tegafur-uracil.

\section{Discussion}

In the management of solid tumors, surgical treatment can remove the primary tumour and any localized disease. However, many patients present with diseasae which has already extended beyond the primary site and thus cannot be eradicated by surgery. It was suggested in the 1970 s that adjuvant treatment of minimal residual disease would provide the best chance of improving the outcome. In western countries, positive results of adjuvant chemotherapy after gastric cancer resection have been regarded skeptically ${ }^{13}$ ). This may explain why most of the studies published after 1985 have been performed in Japan and have generally employed MMC and/or 5-fluorouracil derivatives ${ }^{2-6)}$.

The 7-year survival rate after curative resection of gastric cancer was deternined in this study, and it was found that a rather large number of patients suffered recurrence. Recurrence of gastric carcinoma generally develops within a short time after surgery ${ }^{14)}$, but there have also been reports of late relapse and such cases have increased recently ${ }^{15}$.

The most common classifications of the pattern of recurrence depend on the mode of tumor progression and include localized recurrence, lymphatic recurrence, peritoneal recurrence beyond the range of surgical resection, and hematogenous metastasis ${ }^{15,16)}$. However, as pointed out by Iwanaga et al. ${ }^{15)}$, localized and lymph node recurrence appear to progress to peritoneal and hematogenous recurrence, making it important to study the initial form of tumor relapse. However, since recurrence at multiple sites is common by the time of discovery, all organs affected by recurrence were investigated in this study.

We classified recurrence into four patterns (localized, peritoneal, hematogenous, and lymph node recurrence) based on the site and extent of tumor recurrence. There were few cases of localized recurrences or lymph node metastasis, while peritoneal and hematogenous recurrence were common in both groups, probably because the patients had undergone curative resection.

In patients with gastric cancer who have undergone curative resection, adjuvant therapy with mitomycin $\mathrm{C}$ is reported to be more useful than surgery alone, the most frequent site of relapse is the peritoneal cavity and there is a marked decrease of liver metastases in treated patients ${ }^{5 .}{ }^{5}$. It has also been reported that long-term oral tegafur combined with a short course of high-dose mitomycin $\mathrm{C}$ was more useful than short-term mitomycine $\mathrm{C}$ alone ${ }^{4,6)}$.

In 1975, the Adjuvant Chemotherapy Study Group for Gastric Cancer Surgery was organized on a wide nation scale in Japan. The first study employed mitomycin $\mathrm{C}$ and tegafur administered for 3 months ${ }^{6)}$. In the second study, administration of tegafur was continued for one year ${ }^{4}$.

The survival rate was improved by bolus administration mitomycin C (20 mg on the day of the operation and $10 \mathrm{mg}$ on the following day) and continuous oral tegafur $(600 \sim 800$ $\mathrm{mg} /$ day) for 3 months from the 2 nd week after the operation, and the survival rate was signifiantly improved compared to patients receiving mitomycin $\mathrm{C}$ alone ${ }^{6)}$. In a study on recurrence hazard rates, high-dose mitomycin $\mathrm{C}$ and maintenance therapy with tegafur were shown to be useful in preventing recurrence by peritoneal metastasis in stage III ${ }^{14)}$.

In the second study, short-term administration of mitomycin $\mathrm{C}$ followed by tegafur for one year achieved similar results to those found in the first study. Peritoneal and hematogenous metastasis were inhibited by long-term tegafur, and both the disease-free interval and the survival time were prolonged ${ }^{4}$. However, when the recurrence hazard rates were determined, peaks were seen within $0.5 \sim 1.5$ years for all types of recurrence, and the highest hazard rate was observed for peritoneal metastasis ${ }^{(4)}$.

UFT is an analogue of 5-FU that has been used clinically ${ }^{7}$. Ikenaka et al. ${ }^{18)}$ reported that uracil suppresses the 
degradation of 5-FU but not the phosphorylation of 5-FU in vitro, while UFT has a higher therapeutic ratio and a broader spectrum of antitumor activity than $5-\mathrm{FU}$ in experimental tumors ${ }^{9)}$. When UFT was given to rodents ${ }^{9)}$ or patients ${ }^{4,7)}$, higher levels of 5-FU were found in the blood and tumor tissue compared with administration of tegafur or 5-FU. In a phase II study, the response rate of various tumors was $15.6 \%$ for tegafur and $27.6 \%$ for tegafur-uracil, while the response rates of gastric cancer were $23 \%$ and $30 \%$, respectively ${ }^{17}$. Accordingly, we compared UFT with tegafur as maintenance therapy for patients with stage II, III, or IV gastric cancer ${ }^{3)}$. Short-term mitomycin $C$ therapy was followed by 2 years of tegafur or tegafur-uracil, we found that the 7-year survival rate showed the same trends as the 5year survival rate ${ }^{3)}$.

Although there was no statistical difference, the overall recurrence rate was $39 \%$ in the tegafur group and $24 \%$ in the tegafur-uracil group. Peritoneal and hematogenous recurrence rates were lower in the tegafur-uracil group, but there was no significant difference in the pattern of recurrence. However, some small differences between the groups may exist. To detect a $10 \%$ difference at the $\mathrm{P}<0.05$ levels would require 500 patients in each arm of a trial ${ }^{19)}$, but the clinical relevance of such a difference would be questionable. Thus, these therapies may show significant difference if a larger number of eligible patients are studied.

About $70 \%$ of all recurrences occurred within 2 years in both groups. The risk was highest within 2 years for all modes of relapse, and thereafter fell sharply ${ }^{14-16)}$. This finding indicates that postoperative maintenance therapy for 2 years is necessary to suppress recurrence.

\section{References}

1) Schabel FM. The use of tumor growth kinetics in planning "curative" chemotherapy of advanced solid tumors. Cancer Res, 29 : 2384-2389, 1969

2) Arima S, Futami K, Yoshimura S, et al. Distribution of tegafur in tissues of gastric adenocarcinoma patients : Tissue uptake and concentrations in plasma after oral and rectal administration. Jpn J Clin Oncol, $19: 237-241,1989$
3) Arima $S$, Ohsato $K$, Hisatsugu $T$. Multicentre randomized study of adjuvant chemotherapy with mitomycin $\mathrm{C}$ and tegafur or tegafururacil in gastric cancer. Eur J Surg, $160: 227-232,1994$

4) Hattori T, Inokuchi $K$, Taguchi T, et al. Postoperative adjuvant chemotherapy for gastric cancer, the second report. Analysis of data on 2873 patients followed for five years. Jpn J Surg, $16: 175-180$, 1986

5) Imanaga $\mathrm{H}, \mathrm{Nakasato} H$. Results of surgery for gastric cancer and effect of adjuvant mitomycin $\mathrm{C}$ on cancer recurrence. World J Surg, 1 : 213-221, 1977

6) Inokuchi $K$, Hattori $T$, Taguchi $T$, et al. Postoperative adjuvant chemotherapy for gastric carcinoma. Analysis of data on 1805 patients followed for 5 years. Cancer, $53: 2393-2397,1984$

7) Ota K, Taguchi T, Kimura $K$. Report on nationwide pooled data and cohort investigation in UFT phase II study. Cancer Chemother Pharmacol, $22: 333-338,1988$

8) Palmeri S, Gebbie V, Russo A, Armata MG, Gebbia N, Rausa L. Oral tegafur in the treatment of gastrointestinal tract cancer : a phase II study. Br J Cancer, $61: 475-478,1990$

9) Fujii S, Ikenaga $K$, Fukushima $M$, et al. Effect of uracil and its derivatives on antitumor activity of 5-fluorouracil and 1-(2tetrahydrofuryl)-5-fluorouracil. GANN, 69 : 763-772, 1978

10) Hanaue H, Kurosawa T, Kitano $Y$, et al. Anti cancer drug distribution in lymph and blood during adjuvant chemotherapy after surgery for gastric carcinoma. Cancer, $59: 1571-1576,1987$

11) Japanese Research Society for Gastric Cancer. The General Rules for Gastric Cancer Study in Surgery and Pathology. Jpn J Surg, 11 : $127-145,1981$

12) Gehan EA, Freireich EJ. Non-randomized controls in cancer clinical trials. New Engl J Med, $290: 198-203,1974$

13) Engstrom PF, Lavin PT, Douglas HO, Brunner K. Postoperative adjuvant 5-fluorouracil plus methyl-CCNU therapy for gastric cancer patients. Eastern Cooperative Oncology Group Study (EST 3275). Cancer, $55: 1868-1873,1985$

14) Kaneo Kikuchi, Yasuo Kunii, Shu Kikuchi. The problem of postoperative adjuvant chemotherapy for gastric cancer. Gan To Kagaku Ryoho, 14 : 1136-1142, 1987

15) Iwanaga T, Koyama H, Furukawa H, et al. Mechanism of late recurrence after radical surgery for gastric carcinoma. Am J Surg, $135: 637-640,1978$

16) McNeer, Berg HV Jr, Donn FY, Bowden L. A critical evaluation of subtotal gastrectomy for the cure of cancer of the stomach. Ann surg, $134: 2-7,1951$

17) Estape J, Grau JJ, Lcobendas F, et al. Mitomycin C as an adjuvant treatment of resected gastric cancer, A 10-year follow up. Ann Surg, $213: 219-221,1991$

18) Ikenaka K, Shirasaki T, Kitano S, Fujii S. Effect of uracil on metabolism of 5-fluorouracil in vitro. GANN, $72: 590-597,1981$

19) Freedman LS. Tables of the number of patients required in clinical trials using the log rank test. Stats Med, $1: 121-129,1982$ 